\title{
Biochemical index and immunological function in the peripheral blood of patients with idiopathic pulmonary alveolar proteinosis
}

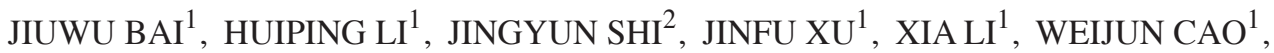 \\ HAIQING CHU ${ }^{1}$, JINMING LIU ${ }^{1}$ and BEILAN GAO ${ }^{1}$ \\ Departments of ${ }^{1}$ Respiratory Medicine and ${ }^{2}$ Radiology, Shanghai Pulmonary Hospital Affiliated to Tongji University, \\ Shanghai 200433, P.R. China
}

Received May 9, 2012; Accepted September 11, 2012

DOI: $10.3892 /$ br.2013.66

\begin{abstract}
Idiopathic pulmonary alveolar proteinosis (PAP) has recently been recognized as a disease of impaired alveolar macrophage function caused by the neutralizing granulocyte-macrophage colony stimulating factor (GM-CSF) autoantibody. However, the change of immunological function and biochemical index in the peripheral blood of patients with idiopathic PAP remains unclear. The clinical data of 29 patients with idiopathic PAP and 30 normal subjects were retrospectively analyzed. Biochemical indices, immunoglobulin and complement of all participants, and immunocytes in 19 patients and 30 normal subjects were evaluated. The peripheral blood of the patients showed a decrease in $\mathrm{CD} 4^{+} / \mathrm{CD} 8^{+}(\mathrm{P}<0.05)$ and the percentage of the $\mathrm{CD} 4^{+} \mathrm{T}$ lymphocyte and helper $\mathrm{T}$ lymphocyte (both $\mathrm{P}<0.01$ ), whereas an increase was observed in the percentage of the suppressor T lymphocyte $(\mathrm{P}<0.01)$ compared to the normal subjects. No significant differences were found in the concentration of $\operatorname{IgG}, \operatorname{IgA}, \operatorname{IgM}, \mathrm{C} 3$ and $\mathrm{C} 4$ between the two groups. An increase was observed in LDH $(\mathrm{P}<0.01)$ and cytokeratin fragment antigen (CYFR) $211(\mathrm{P}<0.01)$ in the peripheral blood of the patients compared to that of normal subjects. The serum level of LDH was negatively correlated with FVC\% Pred $(\mathrm{P}<0.05), \mathrm{D}_{\mathrm{L}} \mathrm{CO} \%$ Pred $(\mathrm{P}<0.05), \mathrm{PaO}_{2}$ $(\mathrm{P}<0.05)$ and positively associated with the dyspnea score $(\mathrm{P}<0.05)$ of 29 patients, and positively correlated with the score of high-resolution computed tomography (HRCT) of the chest of 21 patients $(\mathrm{P}<0.05)$. The serum level of CYFR211 was negatively correlated with $\mathrm{D}_{\mathrm{L}} \mathrm{CO} \%$ Pred $(\mathrm{P}<0.05)$ and positively associated with the dyspnea score $(\mathrm{P}<0.05)$. Findings of the present study suggest that hypofunction of cellular immunity may exist in the patients with idiopathic PAP. LDH and
\end{abstract}

Correspondence to: Professor Huiping Li, Department of Respiratory Medicine, Shanghai Pulmonary Hospital Affiliated to Tongji University, 507 Zheng Min Road, Shanghai 200433, P.R. China E-mail: lihuiping1958@yahoo.com.cn

Key words: idiopathic pulmonary alveolar proteinosis, cellular immunity, cytokeratin fragment antigen 211, lactate dehydrogenase
CYFRA211 may be considered as important indices to monitor the severity of idiopathic PAP.

\section{Introduction}

Pulmonary alveolar proteinosis (PAP), a rare lung disease of unknown origin, is characterized by the accumulation of the alveoli with phospholipid, protein and other floccular material that stain with periodic acid-Schiff. The existence of PAP was only recognized in 1958 through the seminal report of Rosen et al (1). Carey and Trapnell (2) classified PAP into three groups, i.e., congenital, autoimmune and secondary PAP. Congenital PAP is a heterogeneous collection of disorders caused by homozygous mutation of the genes encoding surfactant protein (SP)-B, SP-C and the ABCA3 transporter or by the absence of the granulocyte/macrophage colony stimulating factor (GM-CSF) receptor. Congenital PAP usually occurs in children. Secondary PAP has been reported in association with various diverse clinical disorders such as hematological disorders, immunological diseases, lysinuric protein intolerance and infections, and various toxic inhalation syndromes, including inhalation of inorganic and organic dusts, and fumes. Autoimmune PAP is also regarded as a type of idiopathic PAP.

In this study, idiopathic PAP was employed instead of autoimmune PAP. Ninety per cent of patients have idiopathic PAP, with a prevalence of 6-7 individuals per million in the general population. Additionally, idiopathic PAP occurs in all ethnic groups, in the third to fourth decades of life and is approximately twice as common in males. The presence of idiopathic PAP may be associated with high levels of neutralizing GM-CSF autoantibody $(2,3)$. High levels of GM-CSF autoantibody are associated with idiopathic PAP, and these autoantibodies are assumed to be critical in the pathogenesis of idiopathic PAP, but are not present in secondary or congenital PAP, other lung diseases or in healthy donors (4). The binding affinity of autoantibodies for GM-CSF is higher than that for the GM-CSF receptor in its low- or high-affinity binding state, and these autoantibodies eliminate GM-CSF bioactivity in vivo (5). Subsequently, idiopathic PAP is a type of autoimmune disorder. However, systemic studies regarding the immunological function and biochemical index of idiopathic PAP have yet to be conducted. In the present study, some pathogenesis of 
idiopathic PAP was explored, through the detection of immunocytes, immunoglobulin (Ig), complement (C), cytokeratin fragment antigen 211 (CYFR211), lactate dehydrogenase $(\mathrm{LDH})$ and creatine kinase $(\mathrm{CK})$ in the peripheral blood of patients with idiopathic PAP.

\section{Materials and methods}

Subjects. During the 11-year period between 2000 and 2010, a series of 42 Chinese patients who were diagnosed with PAP in the Shanghai Pulmonary Hospital Affiliated to Tongji University (Shanghai, China) were retrospectively analyzed. In this study, the eligibility criteria used were as proposed by Kavuru et al (6) and included: i) histopathological findings of specimens obtained by open lung biopsy or transbronchial lung biopsy; ii) a milk-like appearance with typical cytologic findings of bronchoalveolar lavage (BAL); iii) high-resolution computed tomography (HRCT) scan which showed ground glass opacity and/or a pattern of crazy paving; iv) restrictive ventilation and diffusion dysfunction, hypoxemia; with v) dyspnea and cough being the most common symptoms, although certain patients were asymptomatic at diagnosis. Exclusion criteria for this study were: i) PAP resulting from another condition (e.g., myeloproliferative disorder or leukemia, occupational exposure to dust, human immunodeficiency virus disease or respiratory infections) and ii) age $<18$ years. The diagnosis of PAP was based on BAL and the histopathological findings of specimens obtained by open lung biopsy in eight patients, by transbronchial lung biopsy in three patients and by only BAL in 31 patients $(6,7)$. Thirteen patients, including 5 steelworkers, 2 mineworkers, 2 steelworkers and 4 persons with long-term contact history to oil fume were excluded from the study. An additional 29 patients had no induction agent, but were diagnosed with idiopathic PAP and included in this study.

Control group. Between 2000 and 2010, 30 healthy adults who had no medical histories were randomly selected following examination in the clinic, and were classified as normal subjects (Table I). All study participants provided informed consent.

Dyspnea score. Dyspnea was one of the most common symptoms. The dyspnea score was measured with the Modified British Medical Research Council (mMRC). The grade of dyspnea was from 0 to 4 (I only get breathless with strenuous exercise, 0; I get short of breath when hurrying on the level or walking up a slight hill, 1; I walk slower than people of the same age on the level due to breathlessness or I have to stop for breath when walking on my own pace on the level, 2; I stop for breath after walking $\sim 100 \mathrm{~m}$ or after a few minutes on the level, 3; I am too breathless to leave the house or I am breathless when dressing or undressing, 4).

Score of chest HRCT. The high-resolution computed tomography (HRCT) of chest was analyzed for 21 patients. The chest HRCT of an additional 8 patients had been examined in other hospitals, but records were inadequate. HRCT scans of the chest were graded according to the visual scoring methods proposed by Lee et al (8). The chest radiographs were read and interpreted independently by a radiologist and a respiratory medicine physician. The mean values obtained from the
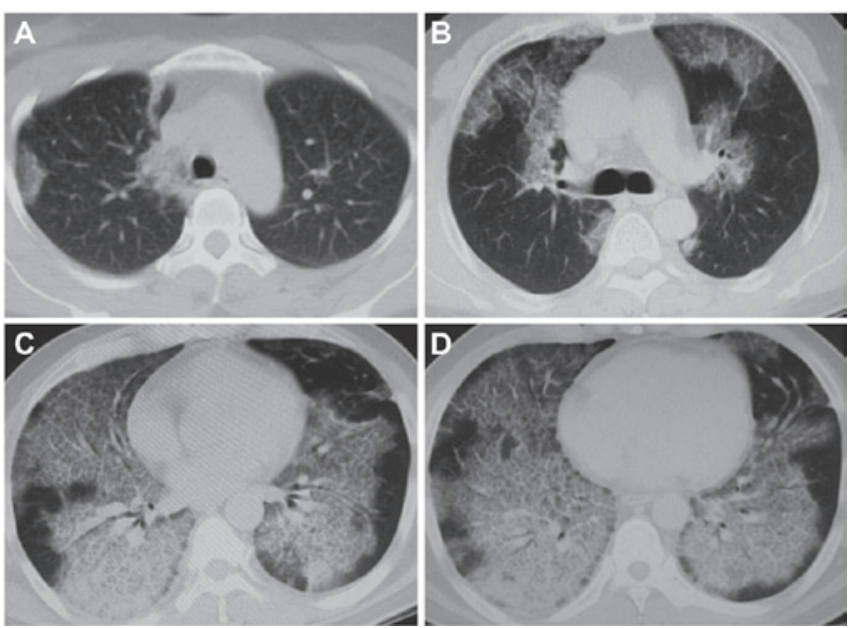

Figure 1. Score on four representative layers. (A) Aortic arch layer score (right, 1; left, 0); (B) tracheal carina layer score (right, 2; left, 2); (C) left/right inferior lung vein converging layer score (right, 4; left, 3); (D) above of the diaphragm layer score (right, 4; left, 3)

two readers were used for analysis. The scores were decided on four representative layers including aortic arch, tracheal carina, left/right inferior lung vein converging and above of diaphragm layer score (Fig. 1). The 'ground glass opacity' referred to the presence of increased lung opacity associated with partial obscuring of normal vascular structures. The extent of lung opacity was estimated by means of a five-point scale as: no opacity, 0 ; opacity involving $<25 \%$ of a layer of hemithorax, $1 ; \geq 25-<50 \%, 2 ; \geq 50-<75 \%, 3 ; \geq 75 \%$, 4 . The score of chest HRCT was calculated by adding up the extent scores on the four representative layers of each hemithorax.

Pulmonary function. The patients and normal subjects underwent pulmonary function testing using a MasterScreen spirometer (Jaeger GmbH, Würzburg, Germany). Pulmonary function testing, including forced vital capacity/predicted value (FVC\% Pred), forced expiratory volume in one second/predicted value $\left(\mathrm{FEV}_{1} \%\right.$ Pred), FEV1/FVC and diffusing capacity of the lung for carbon monoxide/predicted value $\left(\mathrm{D}_{\mathrm{L}} \mathrm{CO} \%\right.$ Pred), was performed. Blood samples were analyzed for arterial partial pressure of oxygen $\left(\mathrm{PaO}_{2}\right)$ values in room air using a Blood-gas analyzer (Radiometer, Copenhagen, Denmark).

Immunological function and biochemistry. Immunocytes in the peripheral blood of 19 patients and normal subjects were detected using a flow cytometer (Beckman Coulter, Inc., Miami, FL, USA). IgG, IgA, IgM, C3, C4, LDH and CK in peripheral blood using a biochemical analyzer (Olympus Optical Co, Ltd., Japan), and CYFR211 in peripheral blood using a full automatic dual-head radioimmunoassay Gamma Counter (Shanghai Hesuo Rihuan Photoelectric Instrument Co., Ltd., China) were detected in all study participants.

Statistical analysis. Differences between the parameters of patients with idiopathic PAP and normal subjects were tested using a paired t-test. $\mathrm{P}<0.05$ was considered statistically significant. All tests were two-sided. Results were reported as 
Table I. Characteristics of the patients and normal subjects.

\begin{tabular}{|c|c|c|c|}
\hline Characteristics & Patients $(n=29)$ & Normal subjects $(\mathrm{n}=30)$ & P-value \\
\hline Gender (male/female) & $19 / 10$ & $20 / 10$ & \\
\hline Mean age (years) & $47.8 \pm 10.6$ & $45.8 \pm 14.1$ & \\
\hline \multicolumn{4}{|l|}{ Smoking status } \\
\hline Current smoker & 11 & 13 & \\
\hline Ex-smoker & 3 & 4 & \\
\hline Never-smoker & 15 & 13 & \\
\hline \multicolumn{4}{|l|}{ Symptom } \\
\hline Dyspnea & 14 & & \\
\hline Dry cough & 11 & & \\
\hline Expectoration & 10 & & \\
\hline Thoracalgia & 5 & & \\
\hline Dyspnea score & $1.17 \pm 1.04$ & & \\
\hline Score of chest HRCT & $19.10 \pm 9.01$ & & \\
\hline FVC\% Pred & $72.26 \pm 19.12$ & $95.97 \pm 8.37$ & 0.000 \\
\hline $\mathrm{FEV}_{1} \%$ Pred & $71.79 \pm 18.36$ & $95.58 \pm 7.83$ & 0.000 \\
\hline FEV1/FVC & $83.09 \pm 5.70$ & $83.47 \pm 5.61$ & 0.655 \\
\hline $\mathrm{D}_{\mathrm{L}} \mathrm{CO} \%$ & $61.56 \pm 24.10$ & $102.49 \pm 11.25$ & 0.000 \\
\hline $\mathrm{PaO}_{2}(\mathrm{mmHg})$ & $71.32 \pm 14.76$ & $94.13 \pm 2.99$ & 0.000 \\
\hline
\end{tabular}

Values are shown as the mean $\pm \mathrm{SD}$. HRCT, high-resolution computed tomography; $\mathrm{FVC} \%$ Pred, forced vital capacity/predicted value; $\mathrm{FEV}_{1} \%$ Pred, forced expiratory volume in one second/predicted value; $\mathrm{D}_{\mathrm{L}} \mathrm{CO} \%$ Pred, diffusing capacity of the lung for carbon monoxide; $\mathrm{PaO} \mathrm{O}_{2}$, arterial partial pressure of oxygen.

the mean \pm SD. The correlation between variables was determined by Pearson's correlation analysis. Statistical analysis was performed using SPSS version 15.

\section{Results}

Patient characteristics. The characteristics of the idiopathic PAP group were compared with those of the normal subjects group (Table I). The mean dyspnea score was shown as $1.17 \pm 1.04$. There were various symptoms, including dyspnea $(n=14)$, dry cough $(n=11)$, expectoration $(n=10)$ and thoracalgia $(n=5)$ in 24 patients, but no symptoms occurred in other patients. The results of pulmonary function and $\mathrm{PaO}_{2}$ are listed in Table I. FVC\% Pred, $\mathrm{FEV}_{1} \%$ Pred, $\mathrm{D}_{\mathrm{L}} \mathrm{CO} \%$ Pred and $\mathrm{PaO}_{2}$ were higher in the idiopathic PAP patients than those of normal subjects (all $\mathrm{P}<0.01$ ). No differences were found in FEV1/FVC between the two groups $(\mathrm{P}>0.05)$. The mean score of chest HRCT of patients was 19.10 \pm 9.01 . Significant correlations between the score of chest HRCT and the dyspnea score ( $\mathrm{r}=-0.857 ; \mathrm{P}=0.000), \mathrm{FVC} \%$ Pred ( $\mathrm{r}=-0.657 ; \mathrm{P}=0.001), \mathrm{FEV}_{1} \%$ Pred $(\mathrm{r}=-0.565 ; \mathrm{P}=0.004), \mathrm{D}_{\mathrm{L}} \mathrm{CO} \%$ Pred $(\mathrm{r}=-0.733 ; \mathrm{P}=0.000)$ and $\mathrm{PaO}_{2}(\mathrm{r}=-0.685 ; \mathrm{P}=0.000)$ were observed in 21 patients. However, no apparent correlations were observed between the score of chest HRCT and FEV1/FVC ( $\mathrm{r}=0.349 ; \mathrm{P}=0.143)$.

Immunological and biochemical indices of the patients and normal subjects, and Pearson's correlation coefficient. The results of immunocytes in peripheral blood are listed in
Table II. The peripheral blood of 19 patients demonstrated a decrease in $\mathrm{CD}^{+} / \mathrm{CD}^{+}(\mathrm{P}<0.05)$, the percentage of $\mathrm{CD}^{+}$ $\mathrm{T}$ lymphocyte $(\mathrm{P}<0.01)$ and helper $\mathrm{T}$ lymphocyte $(\mathrm{P}<0.01)$, and an increase in the percentage of suppressor $\mathrm{T}$ lymphocyte $(\mathrm{P}<0.01)$ compared to that of normal subjects. No correlations were found in the percentage of $\mathrm{CD}^{3+} \mathrm{T}$ lymphocyte, natural killer and $\mathrm{CD}^{+} \mathrm{T}$ lymphocyte between the two groups (all $\mathrm{P}>0.05)$. No correlations were observed between any of factor including $\mathrm{CD}^{4+} \mathrm{T}$ lymphocyte, $\mathrm{CD}^{+} / \mathrm{CD}^{+}$, helper $\mathrm{T}$ lymphocyte and suppressor $\mathrm{T}$ lymphocyte, and the dyspnea score, score of chest HRCT, FVC\% Pred, $\mathrm{FEV}_{1} \%$ Pred, $\mathrm{D}_{\mathrm{L}} \mathrm{CO} \%$ Pred and $\mathrm{PaO}_{2}$, respectively (all $\mathrm{P}>0.05$ ).

Pearson's correlation coefficients (r) between the two variables are listed in Table III. The results of immunoglobulin and complement in peripheral blood are listed in Table II. No differences were observed in the concentration of $\mathrm{IgG}$, IgA, IgM, C3 and C4 between the two groups (all $\mathrm{P}>0.05$ ). The serum level of LDH, CYFRA211 and CK are listed in Table II. An increase was found in the LDH $(\mathrm{t}=7.191 ; \mathrm{P}<0.01)$ and CYFR211 $(\mathrm{t}=5.622 ; \mathrm{P}<0.01)$ in the peripheral blood of the patients compared to that of normal subjects, but there were no differences in the concentration of CK between the two groups ( $\mathrm{P}>0.05)$. The serum level of $\mathrm{LDH}$ was negatively correlated with FVC\% Pred ( $\mathrm{r}=-0.400 ; \mathrm{P}=0.032), \mathrm{D}_{\mathrm{L}} \mathrm{CO} \%$ Pred $(\mathrm{r}=-0.604$; $\mathrm{P}=0.001), \mathrm{PaO}_{2}(\mathrm{r}=-0.395 ; \mathrm{P}=0.034)$, positively associated with the dyspnea score $(\mathrm{r}=0.645 ; \mathrm{P}=0.000)$ in 29 patients with idiopathic PAP, and positively correlated with the score of chest HRCT in 21 patients $(\mathrm{r}=0.494 ; \mathrm{P}=0.023)$. There was 
Table II. Immunological and biochemical index of the patients and normal subjects.

\begin{tabular}{|c|c|c|c|c|c|}
\hline \multirow{2}{*}{$\begin{array}{l}\text { Immunological and } \\
\text { biochemical index }\end{array}$} & \multicolumn{2}{|c|}{ Idiopathic PAP patients } & \multicolumn{2}{|c|}{ Normal subjects } & \multirow[b]{2}{*}{ P-value } \\
\hline & $\mathrm{n}$ & Mean \pm SD & $\mathrm{n}$ & Mean \pm SD & \\
\hline \multicolumn{6}{|l|}{ Immunocytes } \\
\hline $\mathrm{CD}^{+}(\%)$ & 19 & $70.5 \pm 6.0$ & 30 & $68.3 \pm 8.9$ & 0.338 \\
\hline NK (\%) & 19 & $16.2 \pm 17.6$ & 30 & $8.4 \pm 5.5$ & 0.074 \\
\hline $\mathrm{CD}^{ \pm}(\%)$ & 19 & $34.6 \pm 10.6$ & 30 & $44.0 \pm 6.8$ & 0.002 \\
\hline $\mathrm{CD}^{ \pm}(\%)$ & 19 & $28.1 \pm 10.0$ & 30 & $24.9 \pm 7.5$ & 0.210 \\
\hline $\mathrm{CD} 4^{ \pm} / \mathrm{CD} 8^{ \pm}$ & 19 & $1.5 \pm 0.8$ & 30 & $2.0 \pm 0.8$ & 0.033 \\
\hline $\mathrm{Th}(\%)$ & 19 & $0.5 \pm 0.16$ & 30 & $0.6 \pm 0.09$ & 0.001 \\
\hline Ts $(\%)$ & 19 & $0.4 \pm 0.1$ & 30 & $0.3 \pm 0.08$ & 0.009 \\
\hline \multicolumn{6}{|l|}{ Immunoglobulin } \\
\hline $\operatorname{IgG}(\mathrm{g} / \mathrm{l})$ & 29 & $10.7 \pm 3.8$ & 30 & $10.9 \pm 2.1$ & 0.781 \\
\hline $\operatorname{IgA}(\mathrm{g} / \mathrm{l})$ & 29 & $2.7 \pm 1.8$ & 30 & $2.4 \pm 1.8$ & 0.571 \\
\hline $\operatorname{IgM}(g / l)$ & 29 & $1.4 \pm 0.8$ & 30 & $1.1 \pm 0.6$ & 0.104 \\
\hline \multicolumn{6}{|l|}{ Complement } \\
\hline C3 (g/l) & 29 & $1.5 \pm 1.7$ & 30 & $1.2 \pm 0.3$ & 0.330 \\
\hline $\mathrm{C} 4(\mathrm{~g} / \mathrm{l})$ & 29 & $0.4 \pm 0.1$ & 30 & $0.4 \pm 0.2$ & 0.491 \\
\hline \multicolumn{6}{|l|}{ Biochemical index } \\
\hline CYFRA211 (ng/ml) & 29 & $7.0 \pm 4.5$ & 30 & $1.0 \pm 0.6$ & 0.000 \\
\hline LDH (IU/l) & 29 & $239.9 \pm 75.1$ & 30 & $155.3 \pm 31.1$ & 0.000 \\
\hline CK (IU/l) & 29 & $84.3 \pm 69.0$ & 30 & $66.4 \pm 22.4$ & 0.193 \\
\hline
\end{tabular}

$\mathrm{CD}^{+}, \mathrm{CD}^{+} \mathrm{T}$ lymphocyte; NK, natural killer; $\mathrm{CD}^{+}, \mathrm{CD}^{+}{ }^{+} \mathrm{T}$ lymphocyte; $\mathrm{CD} 8^{+}, \mathrm{CD} 8^{+} \mathrm{T}$ lymphocyte; Th, helper $\mathrm{T}$ lymphocyte; $\mathrm{Ts}$, suppressor T lymphocyte; IgG, immunoglobulin G; IgA, immunoglobulin A; IgM, immunoglobulin M; C3, complement 3; C4, complement 4; CYFR211, cytokeratin fragment antigen 211; LDH, lactate dehydrogenase; CK, creatine kinase.

Table III. Pearson's correlation coefficient (r) between the two variables.

\begin{tabular}{lcccc}
\hline Characteristic & $\mathrm{CD}^{+}(\%)$ & $\mathrm{CD}^{+} / \mathrm{CD} 8^{+}$ & $\mathrm{Th}(\%)$ & $\mathrm{Ts}(\%)$ \\
\hline Dyspnea score & 0.180 & 0.294 & 0.232 & 0.402 \\
FVC\% Pred & 0.167 & 0.099 & 0.317 & 0.165 \\
$\mathrm{FEV}_{1} \%$ Pred & 0.113 & 0.007 & 0.230 & 0.233 \\
$\mathrm{D}_{\mathrm{L}} \mathrm{CO} \%$ Pred & 0.264 & 0.270 & 0.286 & 0.434 \\
$\mathrm{PaO}_{2}$ (mmHg) & 0.080 & 0.025 & 0.062 & 0.098 \\
Score of chest & & & & \\
$\mathrm{HRCT}$ & 0.002 & 0.050 & 0.167 & 0.043 \\
\hline
\end{tabular}

FVC $\%$ Pred, forced vital capacity/predicted value; $\mathrm{FEV}_{1} \%$ Pred, forced expiratory volume in one second/predicted value; $\mathrm{D}_{\mathrm{L}} \mathrm{CO} \%$ Pred, diffusing capacity of the lung for carbon monoxide/predicted value; $\mathrm{PaO}_{2}$, arterial partial pressure of oxygen; HRCT, high-resolution computed tomography.

no correlation between $\mathrm{LDH}$ and any of the $\mathrm{FEV}_{1} \%$ Pred $(\mathrm{r}=-0.345 ; \mathrm{P}=0.067)$ or FEV1/FVC ( $\mathrm{r}=-0.140 ; \mathrm{P}=0.468)$, respectively. The serum level of CYFR211 was negatively correlated with $\mathrm{D}_{\mathrm{L}} \mathrm{CO} \% \operatorname{Pred}(\mathrm{r}=-0.401 ; \mathrm{P}=0.031)$, and positively associated with the dyspnea score $(\mathrm{r}=0.403 ; \mathrm{P}=0.030)$. However, no correlation was found between FVC\% Pred ( $\mathrm{r}=-0.256 ; \mathrm{P}=0.180)$, $\mathrm{FEV}_{1} \%$ Pred $(\mathrm{r}=-0.224 ; \mathrm{P}=0.243), \mathrm{FEV} 1 / \mathrm{FVC}(\mathrm{r}=0.309$; $\mathrm{P}=0.103)$ and $\mathrm{PaO}_{2}(\mathrm{r}=-0.171 ; \mathrm{P}=0.374)$ in any of the patients with idiopathic PAP and the score of chest HRCT ( $\mathrm{r}=0.341$; $\mathrm{P}=0.131$ ) of 21 patients.

\section{Discussion}

By summarizing previous studies for over 50 years Carey and Trapnell (2) showed that idiopathic PAP was regarded as being strongly associated with high levels of the neutralizing GM-CSF autoantibody $(9,10)$. Additionally, secondary PAP was associated with various diverse clinical disorders and various toxic inhalation syndromes. Findings of Costabel and Nakata (11) indicated that inhalation of dusts may be the initiating cause which resulted in the elevation of the neutralizing GM-CSF autoantibody. Thus, the cause of idiopathic PAP and the reason for the elevated levels of the GM-CSF autoantibody remain to be investigated.

Dyspnea was observed as the most dominant symptom of patients with idiopathic PAP in Korean and Japanese populations $(9,12)$ and 17 patients in this study $(58.6 \%)$. Results of pulmonary function in this study were similar to those of previous studies (12), i.e., a restrictive defect, with a reduction in the diffusing capacity. Arterial blood gas analysis was 
found to exhibit hypoxemia in previous studies as well as this one $(10,12)$. Chest HRCT objectively showed the degree, extent and severity of lung opacity and was a key external index used to evaluate the severity of PAP. Correlations between pulmonary function testing and HRCT parameters were found by Chen et al (13), with significance in average lung density and FVC, total lung mass and FEV1, the ratio of air-filling lung volume to total lung volume and peak expiratory flow, $\mathrm{D}_{\mathrm{L}} \mathrm{CO}$ and the ratio of $\mathrm{D}_{\mathrm{L}} \mathrm{CO}$ to alveolar volume. Correlation analyses that were performed between quantitative $\mathrm{CT}$ parameters and $\mathrm{D}_{\mathrm{L}} \mathrm{CO}$ and $\mathrm{PaO}_{2}$ by Guan et al (14) indicated that $\mathrm{D}_{\mathrm{L}} \mathrm{CO}$ correlated well with the total lung weight, airspace volume, mean lung density, and mean lung inflation, and that $\mathrm{PaO}_{2}$ also correlated well with the total lung weight, mean lung density, mean lung inflation and airspace volume/total lung volume ratio. In this study, significant correlations were noted between the score of chest HRCT, dyspnea score, and FVC\% Pred, $\mathrm{FEV}_{1} \%$ Pred, $\mathrm{D}_{\mathrm{L}} \mathrm{CO} \%$ and $\mathrm{PaO}_{2}$, respectively. Thus, the severity of idiopathic PAP was reflected by the dyspnea score, score of chest HRCT, pulmonary function and $\mathrm{PaO}_{2}$ to a great extent.

$\mathrm{CD}^{+} \mathrm{T}$ lymphocyte is able to promote the multiplication and differentiation of $\mathrm{B}$ lymphocytes, $\mathrm{T}$ lymphocytes and other immunocytes, and coordinate the interaction between variants of immunocytes. The helper $\mathrm{T}$ lymphocyte is the regulatory $\mathrm{T}$ cell. The suppressor $\mathrm{T}$ lymphocyte is one of the $\mathrm{CD}^{+}$ $\mathrm{T}$ lymphocytes which released inhibitory factors and acted on the antigen-specific helper $\mathrm{T}$ and/or B lymphocyte and led to immunological function suppression. The peripheral blood of the patients showed a decrease in $\mathrm{CD} 4^{+} / \mathrm{CD}^{+}$, the percentage of $\mathrm{CD}^{+} \mathrm{T}$ lymphocyte and helper $\mathrm{T}$ lymphocyte, and an increase in the percentage of suppressor T lymphocyte. These results indicated that cellular immunity was inhibited. The correlation analysis between the significant immunocytes and dyspnea score, score of chest HRCT, lung function index and $\mathrm{PaO}_{2}$, indicated that these immunocytes were not associated with the severity of PAP. However, a predominance of $\mathrm{CD}^{4+}$ cells in some idiopathic PAP cases was reported previously (15). Thus, more studies should be conducted to determine the role of these cells in idiopathic PAP. Results obtained from the analysis of the immunoglobulin and complement indicated that humoral immunity had no correlation with PAP.

The serum level of LDH was increased in idiopathic PAP patients in previous studies $(16,17)$. A significant correlation between LDH and alveolar artery oxygen gradient was detected by $\mathrm{Xu}$ et al (16). In this study, it was also found that LDH was elevated and was correlated with FVC\% Pred, $\mathrm{D}_{\mathrm{L}} \mathrm{CO} \%$ Pred, $\mathrm{PaO}_{2}$, dyspnea score and the score of chest HRCT, suggesting a correlation with the severity of idiopathic PAP. A case of PAP was previously reported in which the value of cytokeratin 19 fragment in the serum was initially elevated and decreased to the normal range after the lung lavage (18). CYFRA211 was the soluble fragment of cytokeratin 19. In this study, the result showed that CYFRA211 increased in PAP, and had a significant cotrelation with $\mathrm{D}_{\mathrm{L}} \mathrm{CO} \%$ Pred and the dyspnea score. Those studies indicated that CYFRA211 may regarded as one of the indices to monitor the severity of idiopathic PAP.

In summary, the results of immunity (including cellular and humoral immunity) and the chemistry index in peripheral blood of patients with idiopathic PAP showed that hypofunction of cellular immunity existed. By contrast, humoral immunity was not involved with idiopathic PAP, LDH and CYFRA211, which may be regarded as important indices to monitor the severity of idiopathic PAP.

\section{Acknowledgements}

This study was supported by grants from the National Natural Science Foundation (30971323) and partly by the Project of Academic Leaders in Excellent Disciplines of Shanghai in China (08XD1403400).

\section{References}

1. Rosen SH, Castleman B and Liebow AA: Pulmonary alveolar proteinosis. N Engl J Med 258: 1123-1142, 1958.

2. Carey B and Trapnell BC: The molecular basis of pulmonary alveolar proteinosis. Clin Immunol 135: 223-235, 2010.

3. Sakagami T,Beck D, Uchida K, et al: Patient-derived granulocyte/ macrophage colony-stimulating factor autoantibodies reproduce pulmonary alveolar proteinosis in nonhuman primates. Am J Respir Crit Care Med 182: 49-61, 2010.

4. Kitamura T, Tanaka N, Watanabe J, et al: Idiopathic pulmonary alveolar proteinosis as an autoimmune disease with neutralizing antibody against granulocyte/macrophage colony-stimulating factor. J Exp Med 190: 875-880, 1999.

5. Uchida K, Nakata K, Trapnell BC, et al: High-affinity autoantibodies specifically eliminate granulocyte-macrophage colony-stimulating factor activity in the lungs of patients with idiopathic pulmonary alveolar proteinosis. Blood 103: 1089-1098, 2004.

6. Kavuru MS, Sullivan EJ, Piccin R, Thomassen MJ and Stoller JK: Exogenous granulocyte-macrophage colony-stimulating factor administration for pulmonary alveolar proteinosis. Am J Respir Crit Care Med 161: 1143-1148, 2000.

7. Borie R, Danel C, Debray MP, et al: Pulmonary alveolar proteinosis. Eur Respir Rev 20: 98-107, 2011.

8. Lee KN, Levin DL, Webb WR, Chen D, Storto ML and Golden JA: Pulmonary alveolar proteinosis: high-resolution $\mathrm{CT}$, chest radiographic, and functional correlations. Chest 111: 989-995, 1997.

9. Inoue Y, Trapnell BC, Tazawa R, et al: Characteristics of a large cohort of patients with autoimmune pulmonary alveolar proteinosis in Japan. Am J Respir Crit Care Med 177: 752-762, 2008.

10. Lin FC, Chang GD, Chern MS, Chen YC and Chang SC: Clinical significance of anti-GM-CSF antibodies in idiopathic pulmonary alveolar proteinosis. Thorax 61: 528-534, 2006.

11. Costabel U and Nakata K: Pulmonary alveolar proteinosis associated with dust inhalation: not secondary but autoimmune? Am J Respir Crit Care Med 181: 427-428, 2010.

12. Byun MK, Kim DS, Kim YW, et al: Clinical features and outcomes of idiopathic pulmonary alveolar proteinosis in Korean population. J Korean Med Sci 25: 393-398, 2010.

13. Chen QL, Shen J, Gao Y, Guan YB, An JY and Zheng JP: Evaluation of correlation between pulmonary function testing and high resolution computed tomography in pulmonary alveolar proteinosis. Zhonghua Jie He He Hu Xi Za Zhi 31: 505-508, 2008 (In Chinese)

14. Guan Y, Zeng Q, Yang H, et al: Pulmonary alveolar proteinosis: Quantitative CT and pulmonary functional correlations. Eur J Radiol: May 26, 2011 (Epub ahead of print).

15. Schoch OD, Schanz U, Koller M, et al: BAL findings in a patient with pulmonary alveolar proteinosis successfully treated with GM-CSF. Thorax 57: 277-280, 2002.

16. Xu KF, Chen Y, Guo ZJ and Zhu YJ: Autoantibody against granulocyte-macrophage colony-stimulating factor and other serum markers in pulmonary alveolar proteinosis. Zhonghua Jie $\mathrm{He} \mathrm{He} \mathrm{Hu}$ Xi Za Zhi 27: 824-828, 2004 (In Chinese).

17. Inoue Y, Nakata K, Arai T, et al: Epidemiological and clinical features of idiopathic pulmonary alveolar proteinosis in Japan. Respirology 11: S55-S60, 2006.

18. Minakata Y, Kida Y, Nakanishi H, Nishimoto T and Yukawa S: Change in cytokeratin 19 fragment level according to the severity of pulmonary alveolar proteinosis. Intern Med 40: 1024-1027, 2001. 